\title{
Prácticas culturales para el manejo de la Sigatoka negra en bananos y plátanos
}

\author{
Mario Orozco-Santos ${ }^{1 *}$, José Orozco-Romero ${ }^{1}$, Octavio Pérez-Zamora ${ }^{1}$, Gilberto Manzo-Sánchez ${ }^{2}$, Javier \\ Farías-Larios $^{2} \&$ Wilson da Silva Moraes ${ }^{3}$
}

${ }^{1}$ Instituto Nacional de Investigaciones Forestales, Agrícolas y Pecuarias - INIFAP, Centro de Investigación Regional del Pacífico Centro, Campo Experimental Tecomán, Apartado postal 88, Tecomán, Colima, 28100 México; ${ }^{2}$ Universidad de Colima, Facultad de Ciencias Biológicas y Agropecuarias, Laboratorio de Biotecnología, Apartado postal 36, Tecomán, Colima, 28100 México; ${ }^{3}$ Universidade Estudual Paulista, Campus Experimental de Registro. 11900-000, Registro, SP, Brasil

Autor para correspondencia: Wilson Silva da Moraes, e-mail: wilson@registro.unesp.br

\begin{abstract}
RESUMEN
El control de la Sigatoka negra (Mycosphaerella fijiensis) se basa en el uso continuo de fungicidas y prácticas de cultivo. El control cultural reduce las fuentes de inóculo del patógeno y las condiciones favorables para su desarrollo, así como incrementa el vigor de las plantas. Para combatir la enfermedad se requiere conocer su comportamiento a través del tiempo, su relación con el clima y las prácticas de manejo. La práctica más importante para reducir la fuente de inóculo es la remoción de hojas afectadas o porciones de éstas. El tejido removido se deposita en el suelo y es factible la aplicación de urea para acelerar su descomposición. Una práctica alternativa es el "minicomposteo", que consiste en colocar la hojarasca y plantas cosechadas en pequeños montones para su rápida degradación, lo cual reduce el inóculo e incorpora nutrientes y materia orgánica al suelo. La poda temprana de las puntas de hojas jóvenes (antes de presentar lesiones esporuladas) y la eliminación rápida de plantas cosechadas disminuyen el inóculo. También, el manejo agronómico del cultivo como densidad de plantación, sistemas de drenaje, métodos de riego, control de malezas, fertilización química-biológica y control de nematodos, ayuda a reducir las condiciones favorables para el desarrollo de Sigatoka negra e incrementar el vigor de las plantas.
\end{abstract}

Palabras clave: control cultural, Mycosphaerella fijiensis.

\begin{abstract}
Cultural practices for the management of black sigatoka in bananas and plantains

Black sigatoka (Mycosphaerella fijiensis) control consists in the continuous use of fungicide sprays and cultural practices. Cultural control reduces inoculum sources of the pathogen and favorable environmental conditions for its development, as well as it increases the vigor of the plants. In order to manage the disease it is necessary to know its behavior through the time, its relationship with the weather and the crop management. The most important cultural practice to reduce the inoculum source is the removal of the whole affected leaves or only the diseased portions of the leaves. The removed tissue is placed over the ground and the use of urea is feasible to accelerate its decomposition. An alternative practice is the "mini-composting" that consists in forming small heaps with the dead leaves and harvested plants for its quick degradation, which allows to reduce the pathogen inoculum and to incorporate nutrients and organic matters into the soil. The early pruning of the tips of the young leaves before they show symptoms of the disease and the quick elimination of harvested plants reduce the inoculum. Also, the agronomic management of the crop helps to reduce the favorable conditions and to increase the vigor of the plants: this management considers plantation density, drainage systems, irrigation methods, control of weeds, chemical-biological fertilization, and nematode control.
\end{abstract}

Keywords: cultural control, Mycosphaerella fijiensis.

\section{INTRODUCCIÓN}

La Sigatoka negra (Mycosphaerella fijiensis Morelet) es la enfermedad más importante que afecta la producción comercial de bananos y plátanos (Musa spp.) en la mayoría de las regiones productoras del mundo (Stover, 1980; Marín et al., 2003). La enfermedad es originaria del sudeste asiático y en el continente americano se identificó por primera vez en Honduras en el año de 1972 (Stover \& Dickson, 1976), de donde se diseminó a todos los países bananeros de América Central, América del Sur, América del Norte y algunas islas del Caribe (Stover, 1980; Marín et al., 2003). La Sigatoka negra ha ocasionado graves pérdidas en la producción comercial de bananos y ha modificado el manejo de las plantaciones, principalmente los programas de control químico. Esto ha traído como consecuencia un incremento en los costos de producción del cultivo. En la actualidad, el combate de la Sigatoka negra en bananos depende principalmente de la aplicación continua de fungicidas (Marín \& Romero, 1992; Orozco-Santos, 1998; Marín et al., 
2003) con las consecuencias fuertemente documentadas, como es el caso de pérdida de sensibilidad de $M$. fijiensis a diversos grupos químicos (Marín et al., 2003), contaminación ambiental y residuos en frutos (Henriques et al., 1997). Esta situación, hace necesario la búsqueda de alternativas para incluirlas dentro de un programa de manejo integrado de la enfermedad. Las prácticas agronómicas tienen un papel importante en el manejo de las plantaciones, ya que permiten proporcionarle las condiciones favorables para el desarrollo de las plantas y evitar un ambiente microclimático propicio para la enfermedad (Pérez, 1998; Orozco-Santos, 1998). Para la producción comercial de bananos y plátanos es necesario contar con un programa de manejo integrado de Sigatoka negra, para lo cual se requiere tener un conocimiento detallado de la enfermedad por parte de técnicos y productores relacionados con la producción de estas musáceas (Orozco-Santos \& Orozco-Romero, 2006). El objetivo de la presente revisión es informar de las diferentes prácticas de cultivo que se deben integrar en un programa de manejo contra la Sigatoka negra en bananos y plátanos basado en la literatura disponible y en experiencias de campo.

\section{EL PATOSISTEMA}

Los patosistemas de cultivos agrícolas están integrados por cuatro componentes principales: hospedero, patógeno, clima y el hombre (Robinson, 1987). En el caso de la Sigatoka negra, 1) Los hospederos económicamente importante son los bananos y plátanos y los daños de la enfermedad dependen de su grupo genómico y cultivares. La mayoría de los cultivares de banano del subgrupo Cavendish son altamente susceptibles (Fouré et al., 2000). La severidad de Sigatoka negra se magnifica en un sistema agrícola como el de estas musáceas, en el cual la propagación vegetativa (reproducción asexual) y el cultivo en grandes extensiones de tierra de una variedad/cultivar genéticamente uniforme, lo hacen altamente vulnerable a ataques epidémicos de la enfermedad (Clay \& Kover, 1996). 2) El agente causal presenta en su ciclo de vida un estado teleomorfo o sexual y un estado anamorfo o asexual. El hongo M. fijiensis es el teleomorfo, mientras que Pseudocercospora fijiensis (Morelet) Deighton es el anamorfo (Mulder \& Stover, 1976; Marín et al., 2003). M. fijiensis produce ascosporas en el interior de pseudotecios sobre lesiones maduras y representan la principal fuente de inóculo de la enfermedad. En cambio, $P$. fijiensis forma conidios en lesiones jóvenes (Stover, 1980; Marín et al., 2003). 3) El clima es un factor importante para el patosistema, al ser un regulador de los procesos biológicos del hospedero y del patógeno. Las precipitaciones elevadas y constantes, así como las temperaturas alrededor de $26-28{ }^{\circ} \mathrm{C}$ poseen un marcado efecto sobre los procesos de infección, germinación, penetración del patógeno y liberación de inóculo (Gauhl,
1994), mientras que el viento favorece su diseminación (Meredith et al., 1973). 4) Finalmente, el hombre forma parte del patosistema al tomar decisiones sobre el uso de determinado cultivar, sistema de producción, manejo del hospedero y métodos de control de Sigatoka negra.

\section{MANEJO INTEGRADO}

El manejo integrado de enfermedades se define como una herramienta sustentable para el combate de patógenos, mediante la combinación de métodos químicos, culturales, físicos y biológicos que minimicen los riesgos económicos, de salud y ambientales (Hollier, 2004). El manejo integrado de Sigatoka negra contempla el uso de diferentes métodos de control apoyado por el conocimiento del cultivar/variedad de banano o plátano (susceptibilidad a la enfermedad, fenología, interacción con el patógeno, órganos afectados y edad de las plantas); del patógeno/enfermedad (especie del hongo, tipo de reproducción, estructura genética, diseminación, fuente de inóculo, sobrevivencia, período de incubación y ciclo de la enfermedad) y clima (cantidad y distribución de la precipitación, temperatura, rocío, radiación solar, nubosidad y humedad relativa) (Orozco-Santos \& OrozcoRomero, 2006). Las prácticas de cultivo están orientadas a reducir las condiciones favorables para el establecimiento y desarrollo del patógeno, inducir el vigor de las plantas, establecer barreras físicas y/o eliminar fuentes de inóculo dentro de la plantación (Moorman, 2004). En el caso del patosistema banano/plátano-Sigatoka negra, el control cultural es una parte fundamental en el manejo de la enfermedad (Marín \& Romero, 1992; OrozcoSantos, 1998). Se han sugerido numerosas prácticas de cultivo dentro de un programa de manejo integrado de la enfermedad, como es el caso de la remoción de hojas afectadas o porciones de éstas; la aplicación de urea y desecantes para acelerar su descomposición, así como la eliminación rápida de plantas cosechadas. Adicionalmente, otros componentes del manejo agronómico del cultivo ayudan a reducir las condiciones favorables (humedad) para el desarrollo de la Sigatoka negra e incrementar el vigor de las plantas: manejo de la densidad de plantación, deshije, sistemas de drenaje, métodos de riego, control de malezas, fertilización química, fertilización biológica (micorrizas y bacterias del género Azospirillum), control de plagas y nematodos (Marín \& Romero, 1992; Orozco-Santos, 1988; Marín et al., 2003; Orozco-Romero et al., 2004). Una práctica alternativa es el "minicomposteo", que consiste en colocar la hojarasca en pequeños montones para su rápida degradación, lo cual permite reducir el inóculo e incorporar nutrientes al suelo (Orozco-Romero et al., 2004). Además, es importante monitorear periódicamente la plantación para conocer el comportamiento de la enfermedad (incidencia, severidad y/o estado evolutivo) y obtener información que auxilie en la toma de decisiones (Marín \& Romero, 1992; Orozco-Santos, 1998). 


\section{PRÁCTICAS DE CULTIVO}

Eliminación total o parcial de hojas afectadas. Esta es la práctica más importante para reducir o eliminar la principal fuente de inóculo (Marín \& Romero, 1992; Orozco-Santos et al., 2002; Marín et al., 2003). Esta práctica, en sus diferentes modalidades se conoce como deshoje (a) o deshojarasque, poda, despunte o cirugía. El deshoje se considera como una poda de sanidad. Las hojas representan la única fuente de inóculo de la enfermedad, por lo que el manejo de éstas es importante para disminuir la esporulación del patógeno a través del tiempo. El propósito de esta práctica es eliminar de manera total o parcial el tejido afectado de las plantas y junto con éste los propágulos del hongo. Las hojas enfermas dejadas en la planta presentan el período más elevado de producción y descarga de ascosporas de M. fijiensis, las cuales pueden sobrevivir y ser liberadas por más de 20 semanas (Gauhl, 1994). En cambio, en la hojarasca depositada en el suelo el patógeno sobrevive de 3 a 6 semanas (Guzmán \& Romero, 1995; Villalta \& Guzmán, 2005). En el suelo, las hojas se descomponen después de 10 semanas, provocando la muerte del patógeno y por consecuencia una menor sobrevivencia de las ascosporas y de liberación de inóculo (Gauhl, 1994). Las cantidades más elevadas de esporulación ocurren en los primeros quince días después de la necrosis del tejido foliar; sin embargo las lesiones de Sigatoka negra continúan contribuyendo a la producción de inóculo hasta después de 30 días de haberse cortado y depositado la hojarasca en el suelo (Villalta \& Guzmán, 2005).

La descarga de ascosporas del tejido foliar enfermo está estrechamente relacionada con factores ambientales, principalmente la precipitación. En regiones de climas húmedos con precipitaciones distribuidas durante todo el año, la liberación de inóculo ocurre prácticamente en todos los meses (Gauhl, 1994; Marín et al., 2003). En cambio, en regiones con clima de trópico seco, la mayor descarga de ascosporas ocurre durante la época de lluvias, mientras que durante la temporada seca la liberación de inóculo es baja (Orozco-Santos et al., 2002). Este comportamiento de la enfermedad hace necesario que el manejo del tejido foliar afectado tenga que ser sumamente estricto durante los períodos lluviosos. El deshoje y acomodo ordenado de las hojas en líneas o montones reduce significativamente el área foliar expuesta a la descarga de ascosporas y disminuye hasta en un $80 \%$ el potencial de producción de inóculo y la severidad de Sigatoka negra (Orozco-Santos et al., 2002). En el trópico seco de México, parcelas de banano Grand Naine sin deshojarascar presentaron epidemias de la enfermedad hasta por siete meses del año, mientras que en parcelas con esta práctica la epidemia duró cinco meses y con un 33\% de menor severidad (Orozco-Santos et al., 2002). Existen reportes contradictorios sobre la importancia de la superficie foliar (haz o envés) en la producción y liberación de inóculo. De acuerdo con Gauhl (1994), no existen diferencias en el número de ascosporas descargadas de lesiones formadas en el haz o envés de las hojas. Otros estudios reportaron una mayor producción de ascosporas en el envés de las hojas de plátano Dominico Hartón (Musa AAB). Contrariamente, Villalta \& Guzmán, (2005) encontraron que en algunos casos la esporulación del hongo fue mayor por el haz de la hoja en banano, lo cual se puede atribuir a la mayor cantidad de pseudotecios maduros por área en esta superficie. Independientemente del lado de la hoja, lo más importante es la eliminación del tejido afectado de la planta y su incorporación al suelo (sin importar su acomodo con el haz o el envés hacia abajo) con la finalidad de acelerar su proceso de degradación. El corte total o parcial de las hojas depende del grado de severidad en las mismas. Si la infección es parcial y no rebasa el $30-40 \%$ del área foliar enferma se sugiere cortar o hacer cirugía del tejido afectado. En cambio, si el grado de infección es mayor, se debe eliminar toda la hoja. Además, se sugiere acomodar las hojas cortadas en el centro de las hileras de plantas, o bien en montones. En ocasiones, los hijos pueden mostrar infecciones fuertes de Sigatoka negra, por lo que se recomienda también cortar estas hojas (Marín \& Romero, 1992; Orozco-Santos, 1998). La frecuencia del deshoje puede ser de una a cuatro semanas, dependiendo de la zona productora, cultivar, clima y presión de la enfermedad.

Bajo condiciones de trópico seco, es factible mejorar el control de Sigatoka negra mediante la reducción del número de aplicaciones de fungicidas. Por la baja liberación de inóculo durante la época seca, se pueden amentar los intervalos de aplicación de fungicidas o inclusive hasta suspenderlas. El deshoje no es muy estricto en huertos con buen drenaje y suficiente aireación, ya que las condiciones de clima no favorecen la descarga de ascosporas. En cambio, en la época de lluvias se deben de tomar estrictas medidas de eliminación de inóculo e integrarlas en un programa de aplicación de fungicidas (Orozco-Santos et al., 2002).

Por otra parte, Merchán \& Chavarriaga (1994) recomiendan en Colombia que el deshoje fitosanitario en plátano 'Hartón' debe realizarse con una periodicidad de cuatro semanas durante la época seca y cada dos semanas en la época de lluvias. En este cultivar se ha demostrado que únicamente con la práctica de deshoje, la Sigatoka negra se puede mantener en niveles de infección bajos. Bajo estas condiciones, con la práctica de deshoje es factible producir fruta de calidad para el mercado interno. Si se desea mejorar la calidad de producción de fruta se deben emplear fungicidas.

En los últimos años se ha venido evaluando $\mathrm{e}$ implementando la práctica de "poda temprana", la cual consiste en la eliminación semanal de la punta de una de las primeras cinco hojas, en un $16 \%$ de su longitud, (aproximadamente $20 \mathrm{~cm}$ ) (Chica et al., 2004). Esta labor se aplica sólo en época de lluvias y tiene como objetivo evitar la presencia de tejido foliar infectado y/o necrosado con propágulos del patógeno. En zonas con una alta intensidad de la enfermedad, es una práctica adicional factible de integrarse en los programas de manejo. 
Tratamientos a la hojarasca. Considerando la importancia del tejido foliar infectado como fuente de inóculo de M. fijiensis, es importante la evaluación de diferentes compuestos aplicados a la hojarasca con la finalidad de disminuir la esporulación del hongo y/o acelerar su proceso de degradación. En Costa Rica, se ha probado el efecto antiesporulante de diferentes compuestos como la urea, el fungicida sistémico propiconazole, glifosato, aceite agrícola, iodo, ceras, el fungicida protectante clorotalonil y mezclas de éstos. El uso de urea al 5\% y la mezcla de urea con glifosato y clorotalonil redujeron la esporulación del hongo hasta en un $80 \%$ con respecto al testigo. Sin embargo, se observó que al someter este mismo tejido foliar a incubación y luego a descargar ascosporas por segunda vez el efecto inhibitorio sobre la esporulación se redujo a un 3040\% (Guzmán \& Romero, 1995). En otros reportes se señala que la aplicación de bacterias, urea y melaza no tuvieron un efecto importante sobre la velocidad de descomposición de las hojas de banano (Guzmán et al., 2005). A las 28 semanas después de colocado el tejido foliar sobre el suelo y de haber recibido tres aplicaciones de los tratamientos en las primeras tres semanas no hubo diferencia significativa. Del mismo modo, la aplicación de estos tratamientos no tuvo un efecto importante en la descarga de ascosporas durante las primeras 3-4 semanas (Guzmán et al., 2005). Sin embargo, en un estudio reciente se demostró que la aplicación semanal de urea al $10 \%$ es una alternativa práctica para reducir las posibilidades de multiplicación del patógeno, sobre todo en condiciones de alta presión de inóculo (Villalta \& Guzmán, 2005). En huertos de banano y plátano, con frecuencia se realizan aplicaciones de fungicidas y aceite agrícola para el control de Sigatoka negra, así como aplicaciones de herbicidas para controlar malezas. Estos productos poseen un reducido efecto sobre la esporulación del hongo. El fungicida sistémico propiconazole y el protectante clorotalonil no parecen tener un efecto importante en la esporulación del hongo en las hojas depositadas en el suelo después de la deshoja sanitaria (Orozco-Santos et al., 2002; Villalta \& Guzmán, 2005). Por otra parte, la aplicación del herbicida desecante paraquat o el aceite agrícola no tuvo efectos significativos sobre el período de producción y la descarga de ascosporas en las hojas (Orozco-Santos et al., 2002). Del gran número de compuestos evaluados sobre la hojarasca en el suelo, el tratamiento que parece más promisorio es la aplicación semanal de urea al 10\% (Villalta \& Guzmán, 2005).

Minicomposteo. Comúnmente los deshechos de las plantas (hojas dobladas, tejido eliminado por el saneo y residuos de cosecha) se esparcen en toda la plantación, lo cual presenta dos inconvenientes: 1) si son hojas con Sigatoka negra: éstas al humedecerse con el agua de riego y lluvia provocan un ambiente favorable que estimula la maduración de los pseudotecios y la esporulación. 2) cuando se deja la hojarasca esparcida en toda la plantación su degradación es muy rápida, lo que conduce a una generación de procesos anaeróbicos por la ausencia de oxígeno, provocando el crecimiento de microorganismos que impermeabilizan y compactan el suelo, el crecimiento de la microflora es lento y solo reciclan los elementos vitales presentes, sin atacar los minerales insolubles. Con este manejo de hojarasca se incorpora una reducida cantidad de materia orgánica (Orozco-Santos \& Orozco-Romero, 2006).

Una alternativa viable es el minicomposteo, el cual consiste en hacer montones con todos los deshechos de las plantas de banano dentro de la plantación. La hojarasca, porciones de hojas que son cortadas y las plantas eliminadas después de la cosecha son apiladas en montones para provocar una rápida degradación y sirvan como aporte de nutrimentos y materia orgánica. Todos los tejidos (hojas y pseudotallo) deben ser cortados para lograr una eficiente descomposición. Los montones de deshechos deben hacerse entre las calles a una distancia de 5 a 6 metros.

Drenaje. Los sistemas de drenaje permiten la rápida eliminación de los excesos de agua dentro del huerto, lo cual además de mejorar el crecimiento del cultivo, reduce las condiciones de alta humedad relativa favorables para el desarrollo del patógeno (Gauhl, 1994; Orozco-Santos \& Orozco-Romero, 2006). Las plantaciones con drenaje deficiente afectan el ritmo de emisión foliar de las plantas y favorecen el desarrollo de Sigatoka negra. En la región Atlántica de Costa Rica, la emisión foliar en plantas de plátano Falso Cuerno (Musa AAB) con problemas de drenaje fue en promedio una hoja cada 9.8 días, mientras que en plantas con buen drenaje la emergencia fue cada 7.6 días (Gauhl, 1994). El tiempo de aparición de síntomas en plantas con y sin problemas de drenaje resultó similar: 17.0 a 28.9 días para pizcas en drenaje limitado y de 15.0 a 26.9 días con buen drenaje. En el caso de manchas, en plantas con problemas de drenaje aparecieron de los 26.0 a 50.7 días y en plantas sin problemas de drenaje fue de 24.6 a 43.6 días (Gauhl, 1994). Sin embargo, el efecto de la Sigatoka negra es mayor en plantaciones con drenaje limitado por el menor ritmo de crecimiento y condiciones de estrés de las plantas.

Manejo del agua y métodos de riego. El riego es una práctica importante en el manejo de las plantaciones de banano y plátano bajo condiciones de trópico seco, ya que gracias a ello se abastece al cultivo del agua necesaria durante la época seca. Con el suministro adecuado de humedad, se desarrollan plantas vigorosas y mantiene un ritmo de emisión foliar normal en los períodos poco favorables para la enfermedad (Orozco-Romero et al., 2004).

En la región productora del estado de Colima, México, se evaluaron seis métodos de riego para determinar su influencia sobre la incidencia y severidad de Sigatoka negra en una plantación en banano de Grand Naine sin aspersión de fungicidas (Tabla 1). Los resultados mostraron que los métodos de riego por aspersión aérea son los que tienen mayor influencia en el desarrollo de la enfermedad. Este tipo de riego tiene un efecto similar al de una lluvia, 
ya que al humedecer el follaje, proporciona las condiciones de agua libre que el hongo requiere para su germinación y penetración. Además, favorece la descarga de ascosporas y ayuda a la diseminación del patógeno. Todos los sistemas de riego subfoliar registraron el mayor daño de la enfermedad y el menor número de hojas funcionales al momento de la floración y cosecha. Los métodos de riego por goteo e inundación presentaron una menor severidad de Sigatoka negra y mayor proporción de follaje sano (Tabla 2).

El sistema que ofrece mayores ventajas es el riego por goteo, ya que utiliza bajos volúmenes de agua, reduce notablemente la infección de la enfermedad y las malezas se desarrollan únicamente en el área humedecida. Contrariamente, el riego por inundación gasta altas cantidades de agua, provoca estrés en las plantas cuando los intervalos de aplicación son mayores de tres semanas y favorece la proliferación de malezas en toda la plantación. El riego subfoliar moja las hojas inferiores de la planta y la hojarasca depositada en el suelo, proporcionado condiciones favorables para la germinación-infección y esporulación del patógeno. Además, gasta volúmenes intermedios de agua y estimula la proliferación de malezas. Estudios previos, han demostrado que la humedad sobre las hojas favorece el desarrollo de la enfermedad (Gauhl, 1994).

Nutrición y fertilidad del suelo. El crecimiento de las plantas de banano y plátano depende de la calidad del suelo. En suelos pobres, la emisión foliar se retrasa y se obtienen plantas más raquíticas. El desarrollo de Sigatoka negra está estrechamente relacionado al crecimiento de la planta hospedera. Mientras más pobre es el crecimiento, la influencia de la enfermedad es más severa. Para lograr un control efectivo de la enfermedad, se deben optimizar todas las condiciones de crecimiento de las plantas (Gauhl, 1994). Asimismo, se ha determinado que la fertilidad del suelo tiene un efecto directo sobre la respuesta del plátano a la incidencia de Sigatoka negra (Mobambo et al., 1994a; Mobambo et al., 1994b). En Nigeria, las plantaciones de plátano (Musa AAB) cultivar Agbagba establecidas en suelos fértiles registraron menor daño que aquellas plantadas en suelos pobres. Las primeras presentaron en promedio 9.3 hojas totales por planta, manchas en la hoja 6.9 y área foliar afectada del $14.1 \%$, en cambio en suelos con baja fertilidad las plantas registraron 7.7 hojas, manchas en la hoja 4.9 y $19.6 \%$ de área foliar enferma (Mobambo et al., 1994b).

El manejo de la fertilización es necesario para mantener el balance de los elementos en niveles óptimos, que aseguren una buena productividad. La aportación adecuada de calcio, magnesio y potasio, así como la relación nitrógeno-potasio permiten obtener plantas vigorosas y no favorecen el desarrollo de la enfermedad (Romero, 1998). Un manejo nutricional que satisfaga los requerimientos del cultivo reduce los factores que lo predisponen a la Sigatoka negra, como es el caso de una nutrición deficiente. Las plantas de banano muestran un alto nivel de tolerancia a la incidencia y severidad de Sigatoka negra cuando las cantidades de nitrógeno son cercanas a los $300 \mathrm{~kg} / \mathrm{ha} / \mathrm{año}$, comparadas con las plantas no tratadas (Méndez, 1998). En Uganda, los bananos fueron menos susceptibles a Sigatoka negra con el incremento de la proporción de potasio: calcio + magnesio, así como por el contenido de materia orgánica en el suelo (Holderness et al., 1999). En México, el banano Grand Naine presentó menor daño de Sigatoka negra cuando se aplicaron 200 kilogramos de nitrógeno por hectárea por año, 75 de fósforo y 150 kilogramos de potasio en comparación a la fertilización con 200 kilogramos de nitrógeno, 150 de fósforo y 300 de potasio. Las parcelas con menor fertilización registraron manchas en la hoja 8.3 con un total de 13.0 hojas, mientras que las fertilizadas con elevadas cantidades de nutrientes mayores, tuvieron manchas en la hoja 7.5 y 12.2 hojas funcionales (OrozcoRomero et al. 2004).

El uso de biofertilizantes en el cultivo del banano produce plantas con mayor desarrollo y emisión de hojas, lo que ayuda a una mayor resistencia de las plantas al daño de Sigatoka negra. En experimentos realizados en México, las plantas de banano tratadas con bacterias del genero Azospirillum y hongos micorrízicos presentaron mejores niveles de tolerancia a la Sigatoka negra ( 8 a $10 \%$ menor severidad) en comparación con plantas con la fertilización química tradicional (Orozco-Santos \& Orozco-Romero, 2006). Por otro lado, cuando se utilizaron los biofertilizantes

TABLA 1 - Características de seis métodos de riego evaluados en banano Grand Naine en el trópico seco de México.

\begin{tabular}{|c|c|c|c|c|c|c|}
\hline Sistema de Riego & & $\begin{array}{c}\text { Gasto } \\
\text { (Lt/hora/emisor) }\end{array}$ & $\begin{array}{c}\text { Distancia entre } \\
\text { emisores (m) }\end{array}$ & $\begin{array}{l}\text { Área de mojado } \\
\text { por emisor }\left(\mathrm{m}^{2}\right)\end{array}$ & $\mathbf{L t} / \mathbf{m}^{2} *$ & $\begin{array}{c}M^{3} \text { de agua } \\
\text { por riego / ha }\end{array}$ \\
\hline & Stell Head & 468 & $9 \times 13$ & 117 & 4.0 & 200 \\
\hline \multirow[t]{2}{*}{ Subfoliar } & Dan Mamkad & 335 & $9 \times 11$ & 99 & 3.4 & 170 \\
\hline & NAAN & 388 & $9 \times 10$ & 90 & 4.3 & 215 \\
\hline Microaspersión & Micro Quick & 65 & $5 \times 3$ & 15 & 4.3 & 215 \\
\hline Goteo & & 0.87 & 0.30 & 0.09 & 2.6 & 52 \\
\hline Inundación o rodado & & - & - & - & 13.2 & 792 \\
\hline
\end{tabular}

* Cantidad de agua que le corresponde a cada metro cuadrado de suelo por una hora de riego 
TABLA 2 - Efecto de diferentes métodos de riego sobre la severidad de Sigatoka negra en banano Grand Naine en el trópico seco de México

\begin{tabular}{llllll}
\hline \hline \multirow{2}{*}{ Sistema de riego } & & \multicolumn{4}{c}{ Sigatoka negra $^{\mathrm{z}}$} \\
\cline { 3 - 6 } & & HMJM & PPI & NHFflor & NHFcos \\
\hline \multirow{2}{*}{ Subfoliar } & Stell Head & $6.2 \mathrm{ab}$ & $2.462 \mathrm{a}$ & $5.6 \mathrm{c}$ & $1.3 \mathrm{c}$ \\
& Dan Mamkad & $6.0 \mathrm{a}$ & $2.499 \mathrm{a}$ & $5.9 \mathrm{c}$ & $1.9 \mathrm{c}$ \\
Microaspersión & NAAN & $5.7 \mathrm{a}$ & $2.800 \mathrm{a}$ & $5.9 \mathrm{c}$ & $1.0 \mathrm{c}$ \\
Goteo & Micro Quick & $6.7 \mathrm{~b}$ & $2.432 \mathrm{a}$ & $9.2 \mathrm{~b}$ & $5.0 \mathrm{~b}$ \\
Inundación o rodado & & $7.3 \mathrm{~b}$ & $1.114 \mathrm{~b}$ & $11.1 \mathrm{a}$ & $8.0 \mathrm{a}$ \\
& & $6.0 \mathrm{a}$ & $1.500 \mathrm{~b}$ & $10.5 \mathrm{ab}$ & $7.8 \mathrm{a}$ \\
\hline
\end{tabular}

$\mathrm{z}=$ Datos promedio de cinco muestreos registrados en Septiembre y Octubre del 2005. Separación de medias según la Prueba de Tukey al 95\% de probabilidad.

HMJM = Hoja más joven con manchas previo a la floración; PPI = Promedio ponderado de infección (Severidad) previo a la floración; NHFflo = Número de hojas funcionales en la floración; NHFcos = Número de hojas funcionales en la cosecha.

se redujo el uso de fertilizantes sintéticos por hectárea, de tal manera que con dos tratamientos de micorrizas y Azospirillum y con solo 100 kilogramos de nitrógeno, 40 de fósforo y 100 de potasio se obtuvieron 70 toneladas por hectárea por año. Una cantidad similar se obtuvo con el uso de los fertilizantes químicos sin biofertilizantes (OrozcoRomero et al., 2004).

Sistema de producción perenne, anual o bianual. En América Latina, el banano se siembra principalmente como un cultivo perenne, en donde existen plantas de todas las edades en todo momento. Esta condición mantiene de manera permanente tejido foliar susceptible a nuevas infecciones por el agente causal de la Sigatoka negra. En contraste, las siembras anuales o en ciclos de dos a cuatro años con lotes de plantas de una misma edad tienen la ventaja de romper el ciclo de la enfermedad al final de la cosecha, lo cual facilita el manejo de los niveles de inóculo y el diseño de estrategias de control más eficientes. Sin embargo, la implementación de cualquiera de los sistemas conlleva a un análisis de beneficios productivos-económicos a corto y mediano plazo, así como las ventajas o desventajas en el manejo de la Sigatoka negra (Romero, 1998).

Densidad de plantación. La alta densidad de siembra de algunos cultivares de banano y plátano es una práctica factible de utilizarse para incrementar la producción por unidad de superficie. La mayoría de los estudios de densidad de plantación, han tenido como objetivo principal el evaluar su influencia en el crecimiento y la productividad de estas musáceas (Álvarez \& Beltrán, 2003; Belalcázar et al., 2003; Langdon et al., 2008). Ocasionalmente, se han considerado parámetros relacionados con la incidencia y severidad de Sigatoka negra. El uso de 3,000 plantas/ha de plátano Dominico-Harton (Musa AAB) en Colombia, incrementó en un $300 \%$ el rendimiento de fruta en comparación al sistema tradicional de 1,000 plantas/ha. Asimismo, un beneficio adicional de este sistema de altas densidades de población es la menor incidencia de Sigatoka negra (Belalcázar et al., 2003). Resultados similares fueron obtenidos en Cuba con el banano FHIA 23 utilizando 4,000 plantas/ha. Con esta población se duplica el rendimiento y disminuye la severidad de Sigatoka negra sin necesidad de hacer aplicaciones de fungicidas, en contraste con huertos comerciales, en donde generalmente se realizan cinco aspersiones de fungicidas (Álvarez \& Beltrán, 2003). La reducción de la severidad de Sigatoka negra se atribuye a la modificación de algunas condiciones ambientales dentro de la plantación (principalmente humedad relativa y temperatura) que afectan la formación de agua condensada sobre las hojas, indispensable para la germinación de los propágulos del hongo. Del mismo modo, se reduce la cantidad de luz en el interior de la plantación, lo cual disminuye la toxicidad de la toxina fotosensible Cercosporín (Belalcázar et al., 2003). Contrariamente, en otros trabajos realizados en Cuba se reportó que el desarrollo de la enfermedad es más intenso con el uso de 2,000 plantas de banano/ha en comparación a 1,850 plantas, registrándose diferencias de hasta dos hojas más sanas en las plantaciones con densidades bajas (Pérez, 1998). Estos contrastes pueden atribuirse al tipo de cultivar de banano o plátano y a las diferencias climáticas en las zonas de estudio, o bien a diferentes microclimas dentro de la plantación: temperatura, aireación, formación de rocío, humedad relativa y radiación solar.

Control de malezas. Existen reportes generales, en donde se señala que un buen control de malezas dentro de las plantaciones permite una aireación adecuada y evita condiciones de alta humedad relativa que favorezcan el desarrollo del hongo. Asimismo, las malezas son nocivas al cultivo de banano y plátano, ya que compiten por agua, nutrientes, espacio y algunas son hospederas de plagas y 
enfermedades (Marín \& Romero, 1992; Orozco-Santos, 1998) Sin embargo, hay poca información disponible sobre el efecto específico de las malas hierbas sobre la severidad de la Sigatoka negra.

Otras prácticas. Otras labores de cultivo que deben ser implementadas dentro de un programa de manejo integrado de la Sigatoka negra son: el deshije, que se utiliza para mantener una población adecuada de plantas y de esta manera evitar el exceso de área foliar e tener mejor cobertura y distribución de los fungicidas aplicados, así como una buena ventilación dentro de la plantación (Stover, 1980; Marín et al., 2003). El combate de nematodos y del picudo, es importante para mantener buena sanidad en la parte subterránea de las plantas (cormo y raíces). Los bananos son más susceptibles a la Sigatoka negra cuando se incrementa la proporción de raíces muertas (menor número de raíces funcionales) por daños de nematodos y área dañada del cormo por el picudo (Holderness et al., 1999). Estas labores, además de mejorar las estrategias de manejo de Sigatoka negra, también optimizan las condiciones del cultivo del plátano.

La alta dependencia de fungicidas para el combate de Sigatoka negra en muchos cultivares de bananos y plátanos, hace necesaria la búsqueda de nuevas alternativas para un manejo integrado de la enfermedad. La evaluación de bioproductos y fungicidas de origen orgánico, son líneas de investigación prioritaria. Por otra parte, las prácticas de cultivo siguen siendo el componente más importante (después del control químico) en el combate de Sigatoka negra, ya que reducen la fuente de inóculo, favorecen el crecimiento del cultivo y disminuyen las condiciones propicias para el desarrollo de la enfermedad. El deshoje, cirugía y poda temprana en sus diferentes modalidades son herramientas útiles para reducir la producción de inóculo; aplicación de urea y minicomposteo para acelerar la descomposición de la hojarasca depositada en el suelo; drenaje y nutrición adecuada; control de nematodos y plagas, entre otras prácticas ayudan a tener plantas vigorosas y menos susceptibles. En cada zona o región bananera se requiere adaptar y adoptar un programa de prácticas culturales basado en el clima, cultivar y severidad de la Sigatoka negra. Para esto, es necesario la realización de estudios continuos, con el objetivo de adoptar las prácticas culturales a la necesidad especifica de cada región.

\section{REFERENCIAS BIBLIOGRAFICAS}

Álvarez JM, Beltrán A (2003) Tecnología de producción con altas densidades en bananos y plátanos en Cuba y avances hacia una producción orgánica. In: Rivas G, Rosales F (Eds.) Taller Manejo convencional y alternativo de la sigatoka negra, nematodos y otras plagas asociadas al cultivo de musáceas en los trópicos. MUSALAC, INIBAP. Guayaquil, Ecuador. pp. 65-66.

Belalcázar CS, Rosales FE, Espinosa MJ (2003) Altas densidades de siembra en plátano, una alternativa rentable y sostenible de producción. In: Rivas G, Rosales F (Eds.) Taller Manejo convencional y alternativo de la sigatoka negra, nematodos y otras plagas asociadas al cultivo de musáceas en los trópicos. MUSALAC, INIBAP. Guayaquil, Ecuador. pp. 55-63.

Chica R, Herrera M, Jiménez I, Lizcano S, Montoya JA, Patiño LF, Rodríguez PA, Ruiz LH (2004) Impacto y manejo de la sigatoka negra en el cultivo de banano de exportación en Colombia. Publicación especial de la XVI Reunión ACORBAT 2004. Oaxaca, México. pp. 53-62.

Clay K, Kover P (1996) Evolution and stasis in plant pathogen associations. Ecology 77:997-1003.

Fouré E, Mourichon X, Jones DR (2000) Evaluating germplasm for reaction to black leaf streak. In: Jones DR (Ed.) Diseases of Banana, Abacá and Enset. Wallingford, UK. CAB International. pp. 62-67.

Gauhl F (1994) Epidemiology and ecology of black sigatoka (Mycosphaerella fijiensis) on plantain and banana (Musa spp.) in Costa Rica, Central America. The International Network for the Improvement of Banana and Plantain. Montpellier, France.

Guzmán M, Romero R (1995) Determinación del efecto antiesporulante de diferentes compuestos sobre Mycosphaerella fijiensis. p. 46. In: Informe anual 1994. Departamento de Investigación y Diversificación Agrícola CORBANA (Corporación Bananera Nacional, CR). San José, Costa Rica.

Guzmán M, Calvo CM, Ovando R, Vargas R (2005) Evaluación preliminar del efecto de la aplicación de bacterias, melaza y urea sobre la degradación de hojas de banano y la esporulación de sigatoka negra en hojas a nivel de suelo. pp. 54-56. In: Informe anual 2004. Dirección de Investigaciones Agrícolas CORBANA (Corporación Bananera Nacional, CR). San José, Costa Rica.

Henriques W, Jeffers RD, Leacher TE Jr, Kendall RJ (1997) Agrochemical use on banana plantations in Latin America: perspectives on ecological risk. Environmental Toxicology and Chemistry 16:91-99.

Holderness M, Bridge J, Gold CS (1999) Pest management in organic systems. In: Hoderness M, Sharrock S, Frison E, Kairo M (Eds.) Organic banana 2000: Towards an organic banana initiative in the Caribbean. INIBAP, CEDAF, CAB International, CTA. Santo Domigo, Dominican Republic. pp. 133-141.

Hollier CA (2004) Integrated pest management. In: Trigiano RN, Windham MT, Windham AS (Eds.) Plant Pathology. Concepts, and laboratory excercises. CRC Press. Boca Raton, Florida, USA. pp. 337-344.

Langdom PW, Whiley AW, Mayer RJ, Pegg KG, Smith MK (2008) The influence of planting density on the production of 'Goldfinger' (Musa spp., AAAB) in the subtropics. Scientia Horticulturae 115:238-243.

Marín DH, Romero RA, Guzmán M, Sutton TB (2003) Black sigatoka: an increasing threat to banana cultivation. Plant Disease 87:208-222.

Méndez BHA (1998) Efecto de seis niveles de nitrógeno, seis de potasio y sus interacciones sobre la incidencia y severidad de Sigatoka negra (Mycosphaerella fijiensis Morelet) en el cultivo de banano, clon 'Gran Enano'. Tesis Ing. Agrónomo. Instituto Tecnológico de Costa Rica, San Carlos.

Merchán VM, Chavarriaga WM (1994) Alternativas de manejo de Sigatoka negra en plátano Hartón (Musa AAB). Memorias de la XI Reunión ACORBAT 1994. pp. 325-335. 
Meredith D, Lawrence J, Firman ID (1973) Ascospore release and dispersal in black leaf streak disease of bananas (Mycosphaerella fijiensis). Transaction British Mycological Society 60:547-554.

Mobambo KN, Zuofa K, Gauhl F, Adeniji MO, Pasberg-Gauhl C (1994a) Effect of soil fertility on host response to black leaf streak of plantain (Musa spp., AAB group) under traditional systems in southeastern Nigeria. International Journal of Pest Management 40:75-80.

Mobambo KN, Zuofa K, Gauhl F, Adeniji MO (1994b) Influence of crop management and soil on plantain (Musa spp., AAB group) response to black sigatoka infection in southeastern Nigeria. Tropicultura 12:43-47.

Moorman G (2004) Cultural control of plant diseases. In: Trigiano RN, Windham MT, Windham AS (Eds.) Plant Pathology. Concepts, and laboratory excercises. Boca Raton, FL. CRC Press. pp. 313318.

Mulder JL, Stover RH (1976) Mycosphaerella species causing banana leaf spot. Transactions of the British Mycological Society 67:77-82.

Orozco-Romero J, Orozco-Santos M, Pérez-Zamora O (2004) Diagnóstico y recomendación nutricional y de riego para banano en el trópico seco de México. Publicación especial de la XVI Reunión ACORBAT 2004. Oaxaca, México. pp. 137-142.

Orozco-Santos M (1998) Manejo integrado de la Sigatoka negra del plátano. SAGAR, INIFAP, CIPAC. Campo Experimental Tecomán. Tecomán, Colima, México. Folleto técnico No. 1.

Orozco-Santos M, Farías-Larios J, Manzo-Sánchez G, GuzmánGonzález S (2002) Manejo integrado de la Sigatoka negra
(Mycosphaerella fijiensis) del banano en el trópico seco de México. Memorias de la XV Reunión ACORBAT 2002. Cartagena de Indias, Colombia. pp. 119-124.

Orozco-Santos M, Orozco-Romero J (2006) Manejo sustentable de sigatoka negra (Mycosphaerella fijiensis) en banano: conocimiento del patosistema, prácticas culturales y control químico. Memorias de la XVII Reunión ACORBAT 2006. Joinville, SC, Brasil. pp. 100-116.

Pérez VL (1998) Control de la Sigatoka negra en cuba: un enfoque de manejo integrado de la enfermedad. INFOMUSA 7:26-30.

Robinson RA (1987) Plant Pathosystems. Berlin, Springer-Verlag.

Romero RA (1998) El control de la sigatoka en producción de banano orgánico. In: Memorias del taller internacional: Producción de banano orgánico y/o ambientalmente amigable. Rosales FE, Tripon SC, Cerna J (Eds). INIBAP, CIID, EARTH. Guácimo, Costa Rica. pp. 173-179.

Stover RH (1980) Sigatoka leaf spot of bananas and plantains. Plant Disease 64:750-755.

Stover RH, Dickson JD (1976) Banana leaf spot caused by Mycosphaerella musicola and M. fijiensis var. difformis: a comparison of the first Central American epidemics. FAO Plant Protection Bulletin 24:36-42.

Villalta R, Guzmán M (2005) Capacidad de esporulación de Mycosphaerella fijiensis en tejido foliar de banano depositado en el suelo y efecto antiesporulante de la urea. In: 1er Congreso Científico Técnico Bananero Nacional. Pococí, Limón, Costa Rica. Resúmen. p. 14.

Recebido 23 Outubro 2007 - Aceito 17 Abril 2008 - TPP 7120

Editor Associado: Francisco F. Laranjeira 